\title{
Performance of Membrane-Assisted Solid Oxide Fuel Cell System Fuelled by Bioethanol
}

\author{
Vorachatra Sukwattanajaroon $^{1}$, Sumittra Charojrochkul ${ }^{2}$, Worapon Kiatkittipong ${ }^{3}$, \\ Amornchai Arpornwichanop ${ }^{1}$, and Suttichai Assabumrungrat ${ }^{1, *}$ \\ 1 Department of Chemical Engineering, Faculty of Engineering, Chulalongkorn University, \\ Bangkok 10330, Thailand \\ 2 National Metal and Materials Technology Center (MTEC), Pathumthani 12120, Thailand \\ 3 Department of Chemical Engineering, Faculty of Engineering and Industrial Technology, \\ Silpakorn University, Nakhon Pathom 73000, Thailand \\ E-mail: Suttichai.a@chula.ac.th
}

\begin{abstract}
The membrane separation units for bioethanol purification including pervaporation and vapor permeation are integrated with the bioethanol-fuelled solid oxide fuel cell (SOFC) system. The preliminary calculations indicate that Hydrophilic type is a suitable membrane for vapor permeation to be installed after a hydrophobic pervaporation. Based on energy self-sufficient condition and data of available pervaporation membranes, the simulation results show that the use of vapor permeation unit after the pervaporation can significantly improve the overall electrical efficiency from $10.96 \%$ for the system with pervaporation alone to $26.56 \%$. According to the effect of ethanol recovery, the ethanol recovery at $75 \%$ can offer the optimal overall efficiency from the proposed purification system compared to the ethanol recovery at $31.16 \%$ for the case with the single pervaporation.
\end{abstract}

Keywords: Solid oxide fuel cell, bioethanol, pervaporation, vapor permeation, process improvement.

ENGINEERING JOURNAL Volume 15 Issue 2

Received 24 December 2010

Accepted 2 March 2011

Published 1 April 2011

Online at http://www.ej.eng.chula.ac.th/eng/

DOI:10.4186/ej.2011.15.2.53 


\section{Introduction}

Membrane technology has become an interesting alternative among the various separation techniques. It has been brought to use in wide ranges of applications covering separation of gas mixtures as well as liquid mixtures. By reason of low energy demand and no limitation on vapor-liquid equilibrium, a membrane enabling separation of azeotropic mixtures [1] is applied to enhance separation performance of distillation column and is then combined into hybrid membranes/distillation process [2] to obtain a concentrated solution. Bioethanol as a part of several renewable resources has been considered as a promising fuel for solid oxide fuel cell because bioethanol can be converted into hydrogen rich gas with a number of reactions i.e. steam-reforming, partial-oxidation, and auto-thermal reforming [3]. Moreover, bioethanol can be derived from many agricultural products. It could become a sustainable fuel instead of fossil fuel. However, bioethanol is inappropriate to be directly applied as a raw material feed for a SOFC system since biomass-derived bioethanol has a low ethanol concentration of 5-12wt $\%$ [4] and the remaining composition contains mainly water. It is necessary to have a bioethanol pretreatment unit to obtain a desired ethanol concentration. In our previous work [5], the distillation column applied as a bioethanol purification unit for the SOFC system was proposed. It was found that the high heat duty demand of reboiler caused the limitation in achieving a high performance of the overall system. Afterwards, low-energy pervaporation was chosen instead of distillation column for bioethanol-fuelled SOFC system to gain better performance [6]. At the based case, the obtained electrical efficiency when using pervaporation was $42 \%$ compared to $34 \%$ of distillation integrated with the system. The results indicated that high ethanol separation factor values of pervaporation were required when the system was operated at high ethanol recovery to obtain its high performance. However, the study did not take into account the availability of the pervaporation membrane materials.

In this paper, a pervaporation based on available membrane materials is considered as a purification unit for SOFC system fuelled by bioethanol to represent more realistic results. In the first part, separation efficiency of pervaporation in each membrane materials is compared at various ethanol recovery parameters. Thereafter, separation performance is further improved by introducing a vapor permeation installed after the pervaporation in order to gain a desired ethanol concentration at a higher ethanol recovery. To serve this specification, selection of appropriate membrane type for vapor permeation is further investigated by considering in real membrane availability and optimal overall efficiency. It is expected that this SOFC system integrated with the proposed purification process could offer a better efficiency.

\section{Modeling and Total System Configuration}

\subsection{Pervaporation}

Pervaporation is a type of membrane-based technology for separation of liquid mixtures. The separation mechanism is relied on the difference in physical-chemical affinity of each permeating species with the membrane material [7]. There are two types of pervaporation membranes including hydrophobic and hydrophilic membranes. Many researches that involve with ethanol-water separation using both types of membranes are summarized in Table 1. By principle, for a dilute bioethanol a hydrophobic membrane should be selected because it requires less thermal energy to vaporize small amount of ethanol permeating through a membrane; however, the availability of high ethanol separation factor is rather limited. In pervaporation, heat taken from sensible heat of liquid feed mixture is necessary for vaporizing a preferential substance to be permeated through the membrane. However, to simplify the calculations, the temperature drop is neglected. Regarding calculation procedures, a number of pervaporation models have been proposed. Various parameters including their criteria are accounted based on theory. To reduce the complexity, this work defines the ethanol recovery parameter representing the influence of other substantial parameters on membrane separation as shown by Eq. (1).

$$
\begin{gathered}
\mathrm{R}_{\mathrm{EtOH}}=\mathrm{f}\left(T_{\text {Feed }}, \text { membrane area, feed composition, permeate side conditions, }, . .\right) \\
=\frac{y_{P(E t O H)} P}{x_{F(E t O H)} F}
\end{gathered}
$$


The mass balance equations over pervaporation are defined as

$$
\begin{gathered}
F=P+R \\
x_{F_{i}} F=y_{P_{i}} P+x_{R_{i}} R
\end{gathered}
$$

where $F$ is the total feed, $P$ is the permeate stream, $R$ is the retentate stream, $x_{\mathrm{i}}$ and $y_{\mathrm{i}}$ represent molar fraction of species $i$ of the retentate and permeate side, respectively.

The separation factor of ethanol over water is another parameter to be employed in the calculation incorporated with ethanol recovery as shown below:

$$
\alpha_{E / w}=\frac{y_{E} / y_{w}}{x_{E} / x_{w}}
$$

\begin{tabular}{|c|c|c|c|c|}
\hline \multicolumn{5}{|c|}{ Hydrophobic membrane } \\
\hline $\begin{array}{l}\text { Membrane } \\
\text { material }\end{array}$ & $\begin{array}{l}\text { Ethanol in feed } \\
\text { (wt.\%) }\end{array}$ & Temperature $(\mathrm{K})$ & $\begin{array}{l}\text { Separation factor } \\
\qquad\left(\alpha_{E / W}\right)\end{array}$ & Reference \\
\hline $\begin{array}{l}\text { Silicalite- } 1 / \alpha- \\
\mathrm{Al}_{2} \mathrm{O}_{3}\end{array}$ & 2 & 348 & 78 & [8] \\
\hline $\begin{array}{l}\text { Silicalite- } \\
\text { 1/Mullite }\end{array}$ & 10 & 333 & 72 & [9] \\
\hline PDMS & 10 & 348 & 6.25 & [10] \\
\hline PTMSP(-silica) & 10 & 348 & 10.7 & [11] \\
\hline $\begin{array}{l}\text { PDMS(ZSM-5 } \\
\text { mixed matrix) }\end{array}$ & 10 & 348 & 15.5 & [10] \\
\hline $\mathrm{ZSM}-5 / \alpha-\mathrm{Al}_{2} \mathrm{O}_{3}$ & 10 & 348 & 24 & [12] \\
\hline \multicolumn{5}{|c|}{ Hydrophilic membrane } \\
\hline $\begin{array}{l}\text { Membrane } \\
\text { material }\end{array}$ & $\begin{array}{l}\text { Water in feed } \\
(\text { wt. \%) }\end{array}$ & Temperature $(\mathrm{K})$ & $\begin{array}{l}\text { Separation factor } \\
\qquad\left(\alpha_{\mathrm{W} / \mathrm{E}}\right)\end{array}$ & Reference \\
\hline Zeolite NaA, disk & 90 & 303 & $>10,000$ & [13] \\
\hline Cellulose ester & 90 & 348 & 0.76 & [10] \\
\hline $\begin{array}{l}\text { NaA, Mullite/ } \\
\mathrm{Al}_{2} \mathrm{O}_{3}\end{array}$ & 10 & 348 & 42,000 & [14] \\
\hline
\end{tabular}

Table 1. Separation performance and selective properties of different membrane types of pervaporation.

\subsection{Vapor Permeation}

This unit is closely similar to pervaporation except that the feed mixture is in vapor phase. When it is installed after a hydrophobic pervaporation, the permeate stream in vapor phase can be directly fed to the vapor permeation unit. Therefore, it can increase separation performance without demanding a large amount of extra thermal energy. The calculation procedure is conducted using the same procedure as mentioned earlier for pervaporation.

There are many methods for generating a driving force for the membrane separation. In this study, a vacuum pump is installed in a permeate side to generate chemical potential gradient for the separation. The electrical power required for operating the vacuum pump is calculated by the following equations:

$$
W_{e, P V}=-m_{p} \int_{T_{\text {in }}}^{T_{o u t}} C_{p} d T
$$




$$
\begin{gathered}
T_{\text {out }}=T_{\text {in }}\left[1+\frac{1}{\eta_{\text {pump }}}\left[\left(\frac{p_{\text {out }}}{p_{\text {in }}}\right)^{\frac{\gamma-1}{\gamma}}-1\right]\right] \\
\gamma=\frac{C_{p}}{C_{p}-R}
\end{gathered}
$$

The electrical efficiency of a vacuum pump is specified at $75 \%$ [15].

\subsection{SOFC System Modeling}

Typically, SOFC operation can be classified into two types of electrolyte; i.e., oxygen ion conducting and proton conducting electrolytes. For the SOFC model, oxygen ion electrolyte type was selected and its electrochemical reaction takes place as below:

$$
\begin{gathered}
\frac{1}{2} \mathrm{O}_{2}+2 \mathrm{e}^{-} \Rightarrow \mathrm{O}^{2-} \\
\mathrm{H}_{2}+\mathrm{O}^{2-} \Rightarrow \mathrm{H}_{2} \mathrm{O}+2 \mathrm{e}^{-}
\end{gathered}
$$

The performance of SOFC was calculated using VBA (Visual Basic for Application) on Excel spreadsheet under the assumption of being operated with a constant operating voltage along the cell length and isothermal condition [16]. The operating voltage $(V)$ is less than the open circuit voltage $(E)$ due to the presence of polarizations. Three types of polarizations were considered in this model: Ohmic, Activation, and Concentration polarizations, respectively. The verification of the model was in good agreement with experimental results of [17], [18] at high hydrogen contents and [19] at low hydrogen contents.

\subsection{System configurations}

Fundamentally, the process of SOFC system fuelled by bioethanol consists of preheaters, reformer, SOFC unit and afterburner. In this study, the extra bioethanol purification unit is added into this system as schematically shown in Fig. 1. Bioethanol as a raw material feed is specified at $10 \mathrm{wt} \%$ or 4.16 mol\% complying with a range of real bioethanol composition [4] at ambient condition before being fed into purification unit operated under $348 \mathrm{~K}$ to achieve a desired ethanol concentration of $25 \mathrm{~mol} \%$, a stoichiometric ratio for ethanol steam reforming reaction [6]:

$$
\mathrm{C}_{2} \mathrm{H}_{5} \mathrm{OH}+3 \mathrm{H}_{2} \mathrm{O} \Leftrightarrow 6 \mathrm{H}_{2}+2 \mathrm{CO}_{2}\left(\Delta H_{298}^{\circ}=+173.5 \mathrm{~kJ} / \mathrm{mol}\right)
$$

Eq. (10) is a main reaction to produce hydrogen rich gas for the system. However, there are undesired reactions occurred simultaneously with the main reaction:

$$
\begin{gathered}
\mathrm{C}_{2} \mathrm{H}_{5} \mathrm{OH}+2 \mathrm{H}_{2} \Leftrightarrow 2 \mathrm{CH}_{4}+2 \mathrm{H}_{2} \mathrm{O}\left(\Delta H_{298}^{\circ}=-157 \mathrm{~kJ} / \mathrm{mol}\right) \\
\mathrm{C}_{2} \mathrm{H}_{5} \mathrm{OH}+\mathrm{H}_{2} \mathrm{O} \Leftrightarrow 4 \mathrm{H}_{2}+2 \mathrm{CO}\left(\Delta H_{298}^{\circ}=+256 \mathrm{~kJ} / \mathrm{mol}\right)
\end{gathered}
$$

The water gas shift reaction (WGSR) can enhance hydrogen production and reduce coke formation via Boudouard reaction from carbon monoxide consumption:

$$
\mathrm{CO}+\mathrm{H}_{2} \mathrm{O} \Leftrightarrow \mathrm{CO}_{2}+\mathrm{H}_{2}\left(\Delta H_{298}^{\circ}=-41.32 \mathrm{~kJ} / \mathrm{mol}\right)
$$

These reactions were assumed to take place isothermally in an external reformer operated at $1023 \mathrm{~K}$ under thermodynamic equilibrium condition. The reformed hydrogen rich gases are then fed into a SOFC to produce electrical power at anode chamber whilst excess air (5 times) is preheated and fed at cathode chamber. Residual gases released from a SOFC containing valuable fuels are brought into the afterburner to combust and recover heat from these residues in order to supply the energy to the other 
heat-demanding units, i.e. purification unit, reformer and preheaters. From Fig. 1, the heat involving in the SOFC and the afterburner represented as $Q_{5}$ and $Q_{6}$ are assigned to have a role in supplying thermal energy to the heat-demanding units represented in $Q_{1}, Q_{2}, Q_{3}$ and $Q_{4}$. The final temperature of exhausted gases released to the environment is assumed at $403 \mathrm{~K}$ [5]. The overall performance of SOFC system is assessed under the condition without external thermal energy demand or $Q_{\text {net }}=0$ calculated by conventional energy balance as shown by Eq. (14):

$$
Q_{n e t}=Q_{5}+Q_{6}-Q_{1}-Q_{2}-Q_{3}-Q_{4}
$$

and the definition of overall electrical efficiency of this system can be shown below:

$$
\eta_{\text {elec }, o v}=\frac{W_{e, \text { net }}}{m o l_{E t O H} \cdot L H V_{E T O H}+\text { External Heat Demand }}
$$

where $W_{\mathrm{e}, \text { net }}$ is the net electrical energy obtained from the system after subtracting power consumption of vacuum pump. $L H V_{\mathrm{EtOH}}$ is the lower heating value of bioethanol feed. From Eq. (14), when $Q_{\text {net }}<0$, the SOFC system requires additional thermal energy from an external heat source and these amounts of heat are taken into account as external heat demand term in Eq. (15) of overall electrical efficiency.

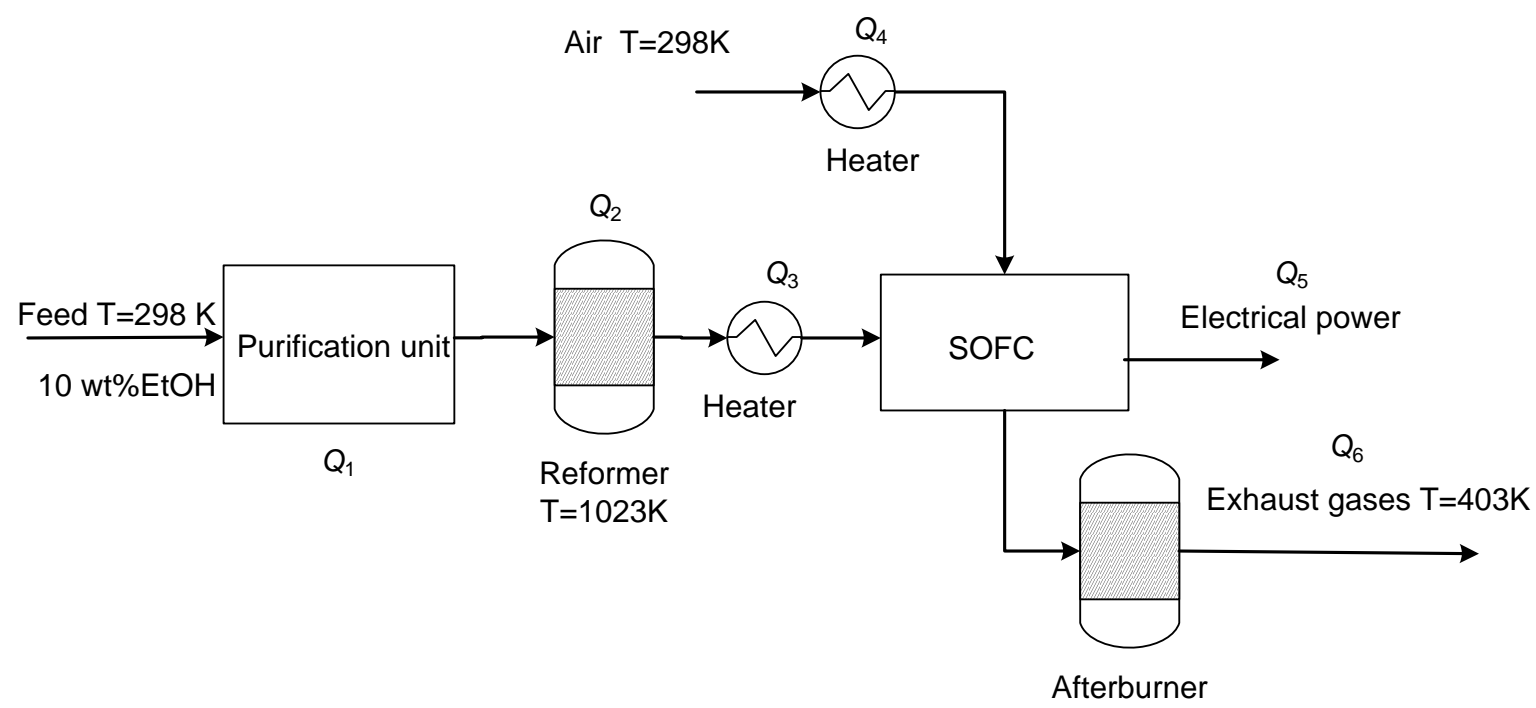

Fig. 1. Schematic diagram of bioethanol-fuelled SOFC system.

For the SOFC system configurations, various bioethanol purification processes were considered as depicted in Fig. 2 including pervaporation alone, pervaporation with hydrophobic vapor permeation and pervaporation with hydrophilic vapor permeation which are placed on a), b) and c), respectively. Hydrophobic membrane is chosen for the pervaporation unit in accordance with a principle mentioned before. Ethanol recovery $\left(R_{\mathrm{EtOH}}\right)$ of vapor permeation in cases b) and c) are defined at $99 \%$. To consume less electrical power, the vacuum pumps of both pervaporation and vapor permeation are assumed to be operated at $0.15 \mathrm{~atm}$ which is feasible in practical operation.

For case a), the hydrophobic pervaporation is used to remove ethanol from the feed by permeating through a membrane. The separation depends on the membrane's ethanol separation factor. Considering case b), the hydrophobic vapor permeation is installed after the pervaporation to obtain a permeate stream of $25 \mathrm{~mol} \%$ ethanol at a higher ethanol recovery. On the other hand, the hydrophilic vapor permeation in case c) is used to remove excess steam permeating through the membrane until the retentate side of the vapor permeation contains of $75 \mathrm{~mol} \%$ water. It was assumed that heat available in the permeate stream can be recovered until its exhaust temperature of $403 \mathrm{~K}$ [5]. 
a)

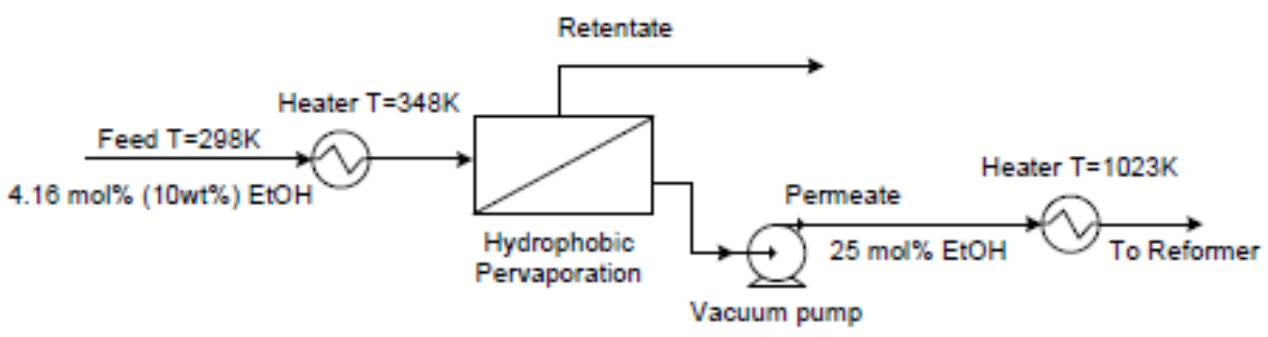

b)

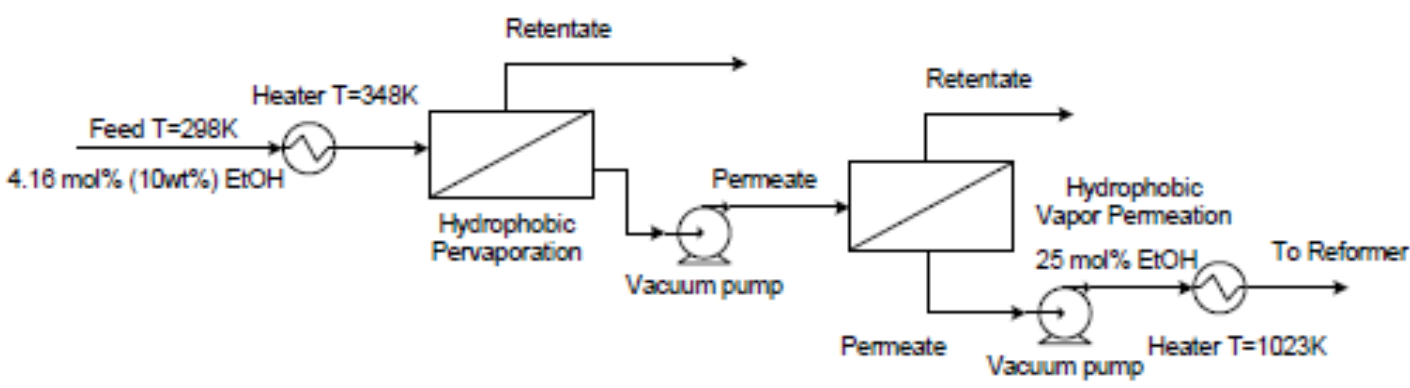

c)

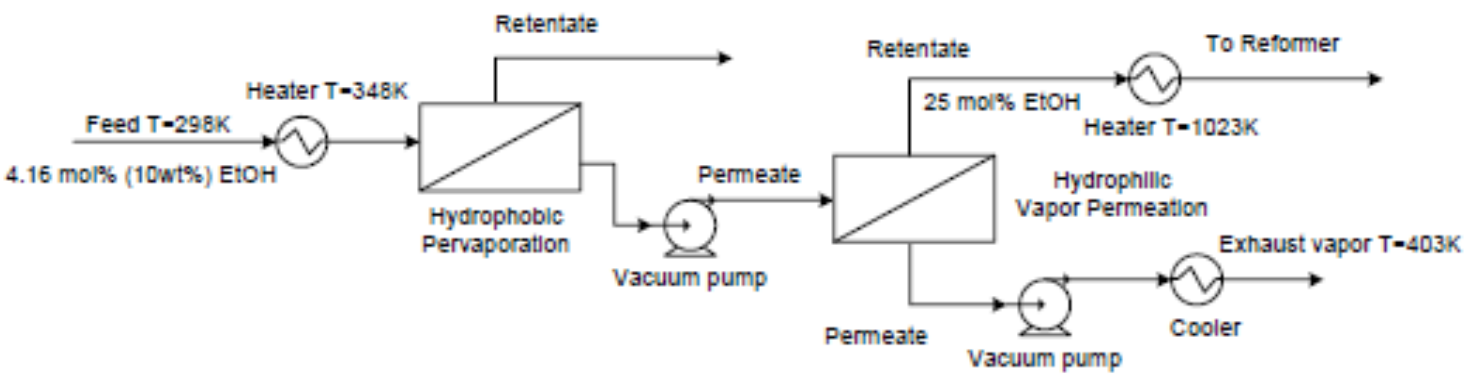

Fig. 2. SOFC system configuration: (a) pervaporation, (b) pervaporation with hydrophobic vapor permeation, (c) pervaporation with hydrophilic vapor permeation.

\section{Results and Discussion}

\subsection{Effects of Ethanol Recovery and Membrane Material on Ethanol Concentration in Hydrophobic Pervaporation}

Separation performance of hydrophobic pervaporation was assessed based on performance of real membrane materials as summarized in Table 1. The selected membranes are PDMS, PTMSP, PDMS (ZSM-5 mixed matrix) and ZSM-5 $\left(\alpha-\mathrm{Al}_{2} \mathrm{O}_{3}\right)$ which offer ethanol separation factor values of 6.25, 10.7, 15.5, and 24, respectively. The results illustrate that when increasing ethanol recovery of pervaporation, the obtained ethanol concentrations from all membranes are declined as illustrated in Fig. 3. For membranes with low ethanol separation factor such as PDMS with $\alpha_{\mathrm{E} / \mathrm{w}}=6.25$, the desired ethanol concentration $(25 \mathrm{~mol} \%)$ cannot be achieved at any ethanol recovery even at low recovery values. Considering the other three membranes, PTMSP membrane whose ethanol separation factor is 10.7, just a little higher than PDMS, merely obtains $25 \mathrm{~mol} \%$ ethanol at $31.16 \%$ ethanol recovery. For PDMS(ZSM-5 mixed matrix) and ZSM-5 $\left(\alpha-\mathrm{Al}_{2} \mathrm{O}_{3}\right)$ membranes, they can provide 25 mol\%ethanol with more than $50 \%$ ethanol recovery (54\% and $71 \%$, respectively). At high ethanol recovery such as $95 \%$, Fig. 3 shows that there is no significant difference in the obtained ethanol concentration among all membranes regardless of membrane separation factor values. As a result of increasing ethanol recovery, 
a high ethanol separation factor values for hydrophobic pervaporation should be required in order to achieve the desired ethanol concentration with high ethanol recovery.

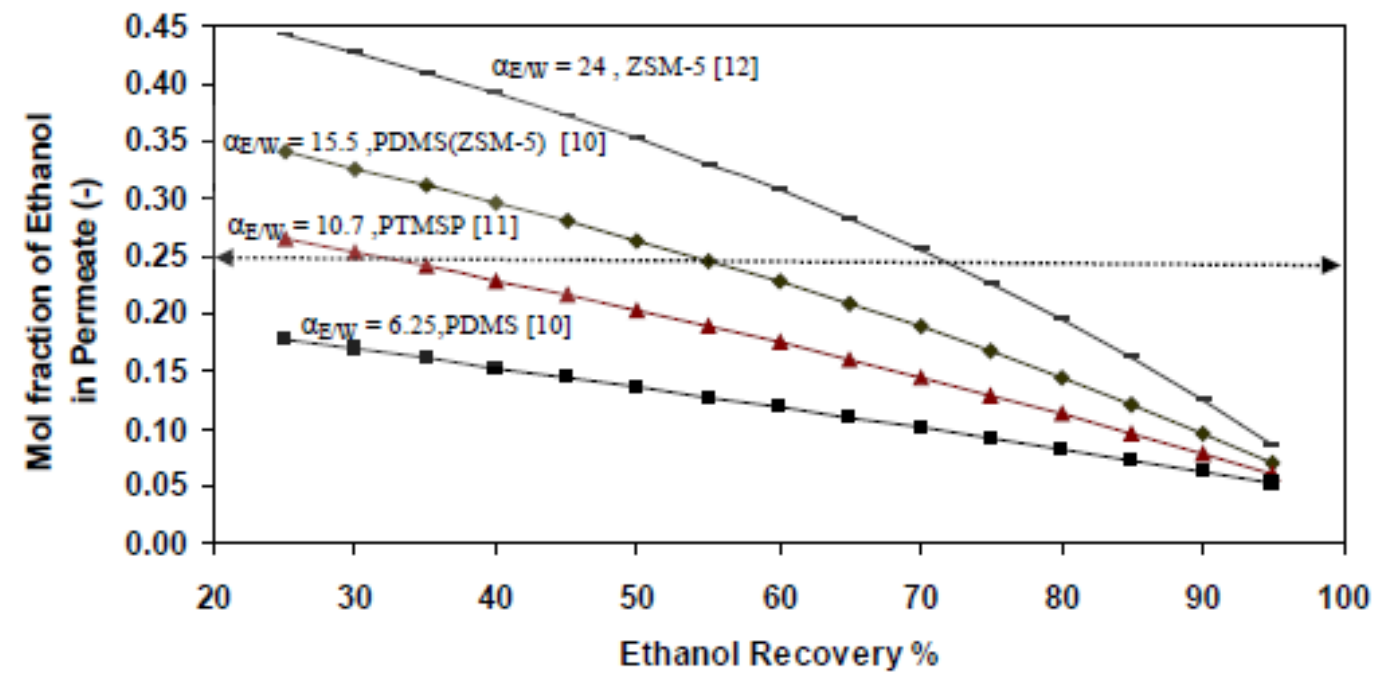

Fig. 3. Effect of ethanol recovery on the obtained ethanol concentration using hydrophobic membranes.

\subsection{Performance comparison between different vapor permeation membrane types}

According to the previous results in Fig. 3, it is clear that due to the low separation factor of the hydrophobic membrane for pervaporation, the desired ethanol concentration of $25 \%$ can only be achieved with some membrane materials but the obtained ethanol recovery is still low. To improve its poor separation performance, a vapor permeation installed after the pervaporation is proposed. The effect of membrane types (hydrophobic and hydrophilic) is investigated. PTMSP membrane having the lowest ethanol recovery at the desired ethanol concentration which was regarded as a worst case is considered to be a reference case study in this section in order to clearly demonstrate its performance improvement.

\subsubsection{Effect of pervaporation ethanol recovery on the required vapor permeation separation factor and permeate flow rate}

Figure 4 shows the permeate flow rates of the hydrophobic and hydrophilic vapor permeations at different values of pervaporation ethanol recovery of PTMSP $\left(\alpha_{\mathrm{E} / \mathrm{W}}=10.7\right)$-based membrane. The ethanol recovery in vapor permeation was specified at $99 \%$. It can be observed that the permeate flow rates of the hydrophobic type increase gradually when increasing pervaporation ethanol recovery, whereas for the hydrophilic type whose desired ethanol composition of $25 \mathrm{~mol} \%$ appears at the retentate stream, the permeate flow rate increases rapidly with increasing pervaporation ethanol recovery. At low range of pervaporation ethanol recovery, the values are smaller than those of the hydrophobic membrane but the opposite trend is observed at higher ranges of pervaporation ethanol recovery. The upper $\mathrm{x}$-axis of Fig. 4 shows the obtained ethanol mol fraction in permeate stream of the pervaporation. The values decline from the desired ethanol concentration when increasing ethanol recovery higher than $31.16 \%$. The right $y$-axis of Fig. 4 indicates that it requires a higher membrane separation factor for vapor permeation when increasing the pervaporation ethanol recovery. The value of the vapor permeation separation factor increases above 100 at ethanol recovery greater than $70 \%$. At a higher range of ethanol recovery (80-99\%), the both cases require much higher separation factor to serve their conditions. Based on the principle stated by Wijmans and Baker [20], they claimed that permeability data of pervaporation can be applied as a preliminary estimation for vapor permeation. Therefore, from the results shown in Fig. 4, it indicates that the required ethanol separation factor values for hydrophobic type are not available in commercial membranes. On the contrary, the obtained water separation factor of hydrophilic vapor permeation is available in real membranes according to the high $\alpha_{\mathrm{W} / \mathrm{E}}($ Table 1$)$. 


\section{Ethanol mol fraction in permeate $\mathrm{pv}(-)$}

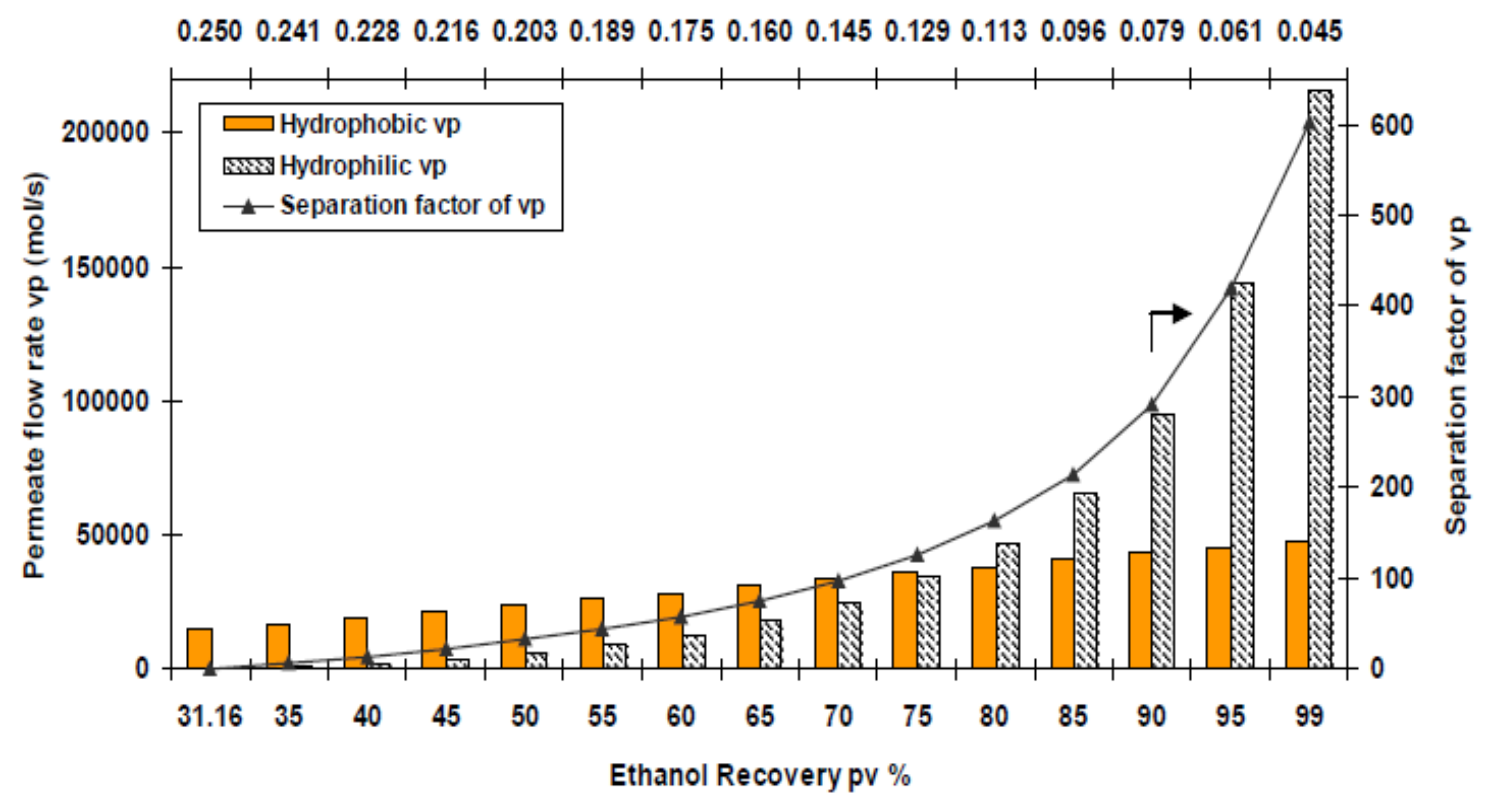

Fig. 4. Effect of ethanol recovery of PTMSP pervaporation on permeate flow rate between two types and separation factor of vapor permeation.

\subsubsection{Effect of pervaporation ethanol recovery on energy consumption}

The results of energy requirement including thermal and electrical energy are presented in Fig. 5. Three SOFC systems (i.e. pervaporation alone, pervaporation with hydrophobic vapor permeation and pervaporation with hydrophilic vapor permeation) were considered. For hydrophobic pervaporation, the demand of thermal energy is the highest compared to the other two cases especially at high ethanol recovery but it requires the lowest electrical power. Considering the other two cases, at low range of ethanol recovery, the integration with the hydrophilic vapor permeation consumes thermal energy a little higher than the other case. However, when the ethanol recovery is further increased, the demand of thermal energy does not significantly increase and it becomes lower than that of the hydrophobic vapor permeation at $70 \%$ ethanol recovery. Although the hydrophilic vapor permeation requires lesser thermal energy, it consumes higher electrical power.

\subsection{Performance of SOFC systems at appropriate operating conditions}

\subsubsection{Effects of SOFC operating voltage and fuel utilization on the net thermal energy $\left(Q_{n e t}\right)$}

From the above studies, the proposed purification process can offer the desired ethanol concentration at higher ethanol recovery by using integrated pervaporation and vapor permeation. Pervaporation with poor ethanol separation factor recovers high amount of ethanol but the ethanol concentration is still lower than the desired concentration. Then, the permeate stream was purified by vapor permeation to reach $25 \mathrm{~mol} \%$ of ethanol. However, electrical power consumption was required further from a vacuum pump of vapor permeation as shown in Fig. 5. Therefore, in this section, it is necessary to evaluate the overall performance focusing on the net thermal energy $\left(Q_{\text {net }}\right)$ obtained from the SOFC systems integrated with the proposed purification process. The effects of fuel utilization $\left(U_{\mathrm{f}}\right)$ and operating voltage $(V)$ on $Q_{\text {net }}$ are presented in Figs. 6 and 7 for high and low ranges of ethanol recovery for both types of vapor permeation, respectively. At high ethanol recovery, Fig. 6a) referring to the hydrophobic type shows that there is a narrow range of fuel utilization values which can be operated above $Q_{\text {net }}=0$, while Fig. 6b) referring to the hydrophilic type shows a wider range of fuel utilization values which can offer that condition and has the remaining heat higher than the other one at the same fuel utilization and operating voltage. At low ethanol recovery, Figs. 7a) and 7b) show slightly difference in net thermal energy between the hydrophobic and hydrophilic types, indicating that the hydrophilic vapor 
permeation provides the net thermal energy slightly lower than the hydrophobic vapor permeation. However, this section only investigates the feasibility of operating conditions that can serve $Q_{\text {net }} \geq 0$. Electrical efficiency is another important performance indicator of the system to be evaluated further in the next section.

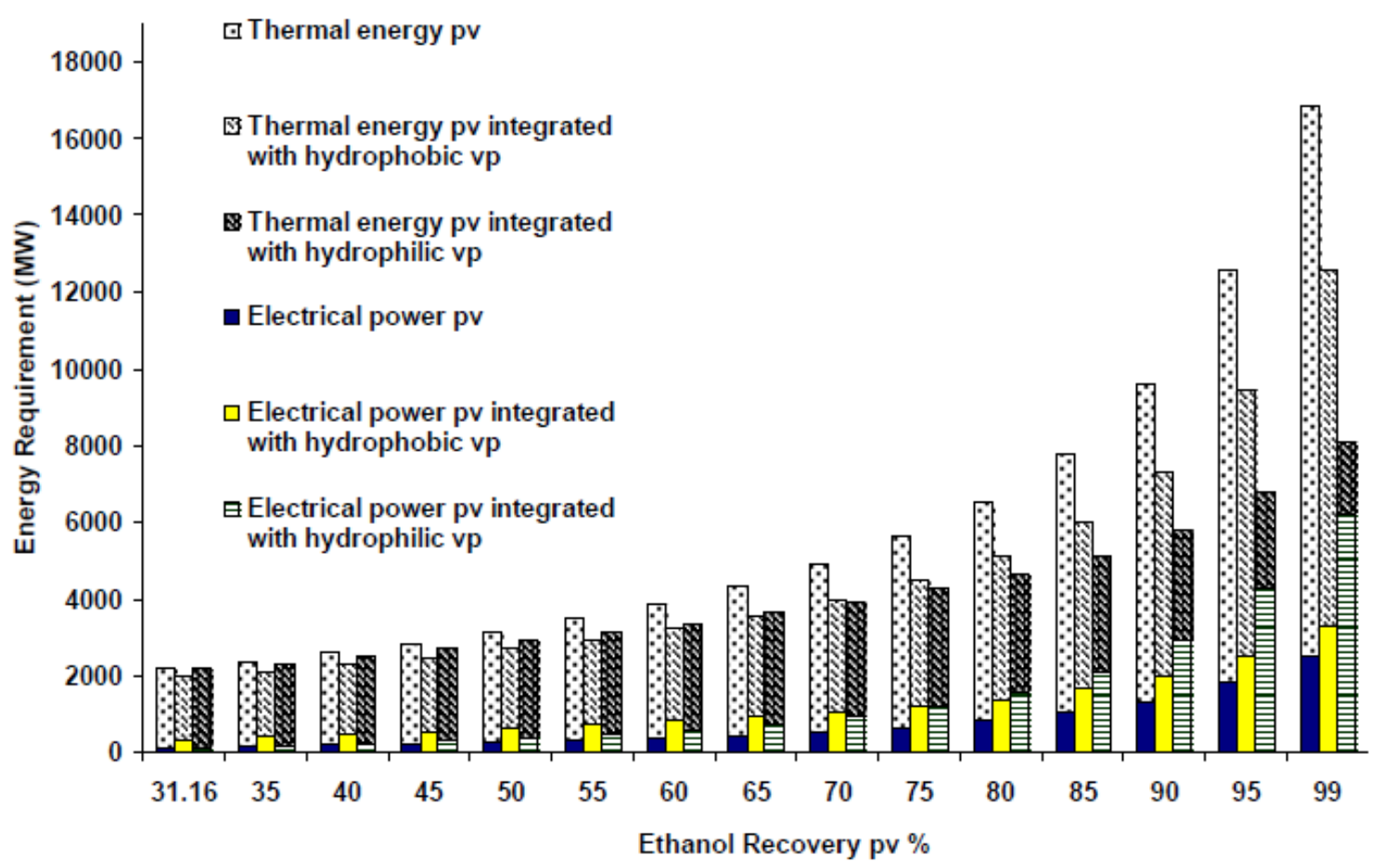

Fig. 5. Effect of ethanol recovery of PTMSP pervaporation on energy requirement of both types of vapor permeation.

\subsubsection{Optimal efficiency comparison between SOFC systems with two different membrane types of vapor permeation at the condition of $Q_{\text {net }}=0$}

In order to operate the SOFC without demanding additional energy from an external source and to achieve the highest electrical efficiency, the system should be operated at the condition with net thermal energy $\left(Q_{\text {net }}\right)$ equal to zero. From the previous section, it is feasible to operate the SOFC system with the proposed purification process under this condition. In this section, electrical efficiency comparison between the SOFC systems with hydrophobic and hydrophilic vapor permeation is studied at various values of pervaporation ethanol recovery to determine a suitable purification system for operation. From Fig. 8, the results obtained from simulation studies are based on the following operating conditions: Operating voltage $=0.6 \mathrm{~V}$ and $T_{\mathrm{SOFC}}=1073 \mathrm{~K}$. It should be noted that the SOFC stack can be operated at other values of operating voltage; however, based on the energy self-sufficient condition in this work, the overall electrical efficiency does not vary with the operating voltage. At higher operating voltage, although the SOFC stack efficiency is higher, the lower fuel utilization is required in order to leave sufficient fuel for generating enough heat at the afterburner for use within the system. It is found that the overall electrical efficiency gradually increases when increasing ethanol recovery up to $75 \%$. At higher ethanol recovery, the energy requirement including thermal and electrical energy for purification system rapidly increases as shown in Fig. 5. Accordingly, the overall electrical efficiency drops dramatically especially in case of the hydrophobic type represented by dash line. The system with hydrophobic type offers the overall system efficiency lower than that with the hydrophilic type because its summation of energy consumption including thermal and electrical energy is higher than that of the hydrophilic type especially at high ethanol recovery as illustrated in Fig. 5. As shown in Fig. 8, it is found that the optimal overall electrical efficiency obtained from the hydrophilic type was $26.56 \%$ at $75 \%$ ethanol recovery. 


\subsubsection{Efficiency comparison of SOFC systems between with and without vapor permeation}

After we obtained a suitable purification system from the above studies, the overall electrical efficiencies for the SOFC systems with and without vapor permeation are compared in this section based on the following operating conditions: Operating voltage $=0.6 \mathrm{~V}$ and $T_{\mathrm{SOFC}}=1073 \mathrm{~K}$. According to the use of PTMSP pervaporation with $\alpha_{\mathrm{E} / \mathrm{w}}=10.7$ as a based case, Table 2 shows the results when installing the hydrophilic vapor permeation which is a suitable choice to be installed after the pervaporation. The obtained electrical efficiency is $26.56 \%$ compared to $10.96 \%$ of the SOFC with pervaporation alone because it can recover amount of ethanol at $75 \%$ while the based case can only recover ethanol at $31.16 \%$ for $25 \mathrm{~mol} \%$ ethanol concentration.

a)

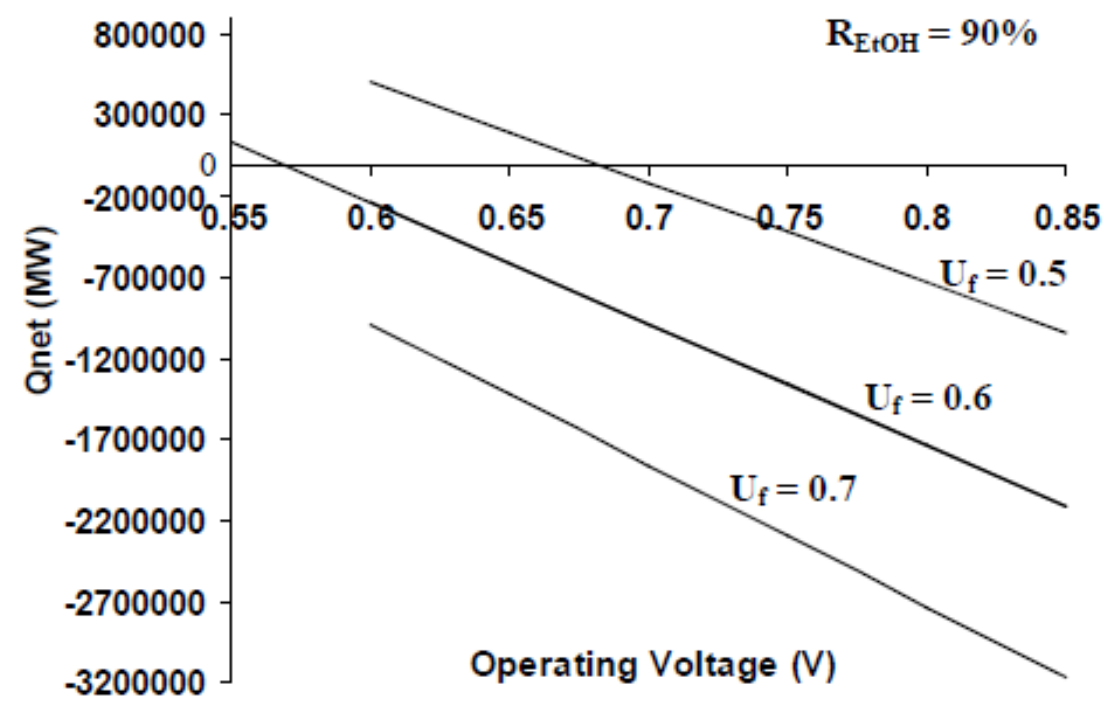

b)

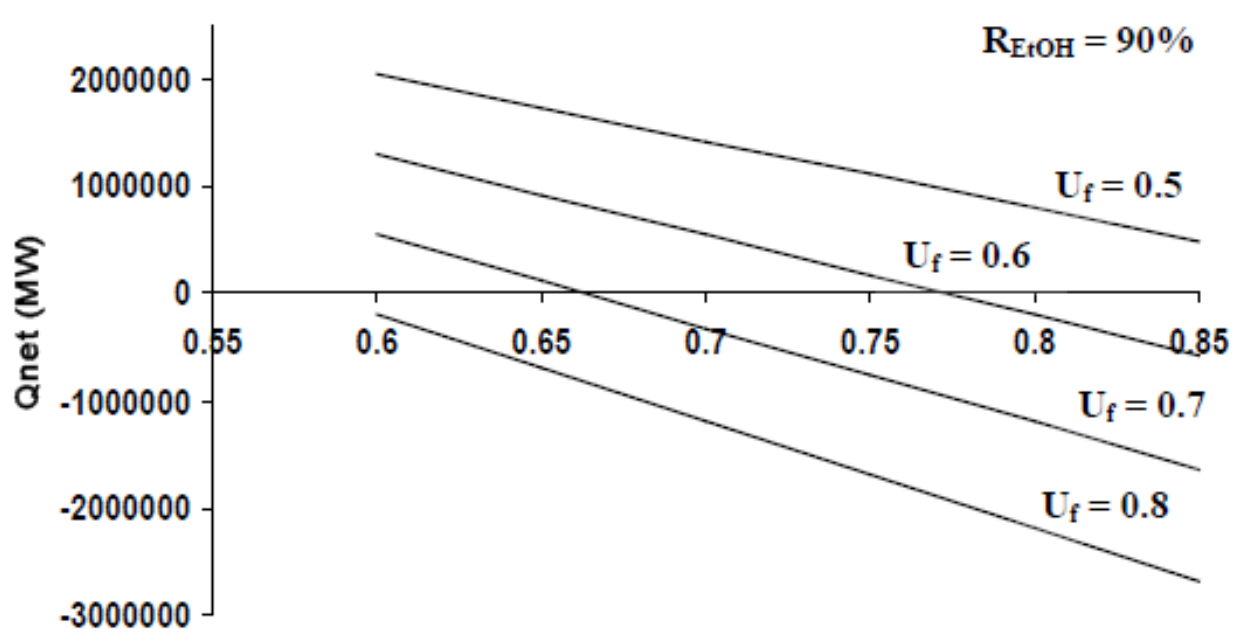

Operating Voltage $(\mathrm{V})$

Fig. 6. Effects of operating voltage and fuel utilization on $\mathrm{Q}_{\text {net }}$ at high ethanol recovery: (a) Hydrophobic vapor permeation, (b) Hydrophilic vapor permeation.

Although the additional vapor permeation requires electrical power for operating vacuum pump, it still obtains the net electrical power $\left(W_{\mathrm{e}, \mathrm{net}}\right)$ higher than the case with single pervaporation because of no heat consumption requirement in separation for vapor permeation as mentioned earlier and the extra electrical power consumption takes a little effect on the overall efficiency. Therefore, the system does 
not significantly reduce the fuel utilization values. Moreover, it can be observed that the addition of vapor permeation system has the overall electrical efficiency which can overcome the case of PDMS(ZSM-5 mixed matrix) with $\alpha_{E / \mathrm{w}}=15.5$. Nevertheless, it should require higher ethanol separation factor values of hydrophobic pervaporation for a desired ethanol concentration at high ethanol recovery in order to gain higher overall system efficiency as seen in the case of ZSM-5/ $\alpha-\mathrm{Al}_{2} \mathrm{O}_{3}$ which shows electrical efficiency of $34.02 \%$.

a)

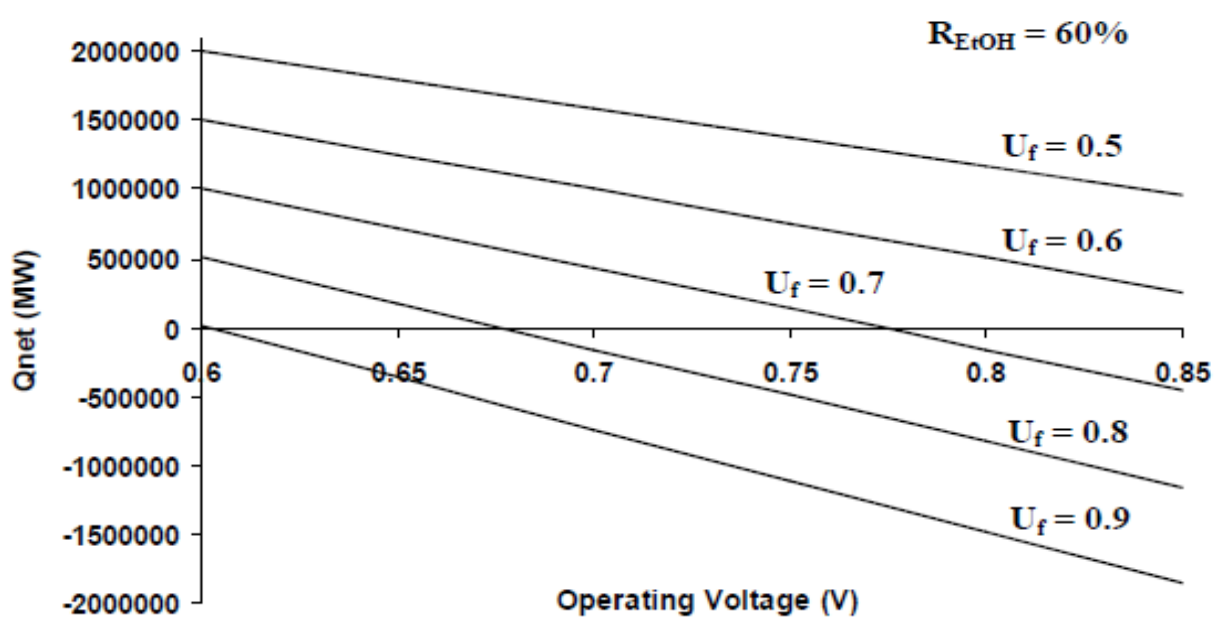

b)

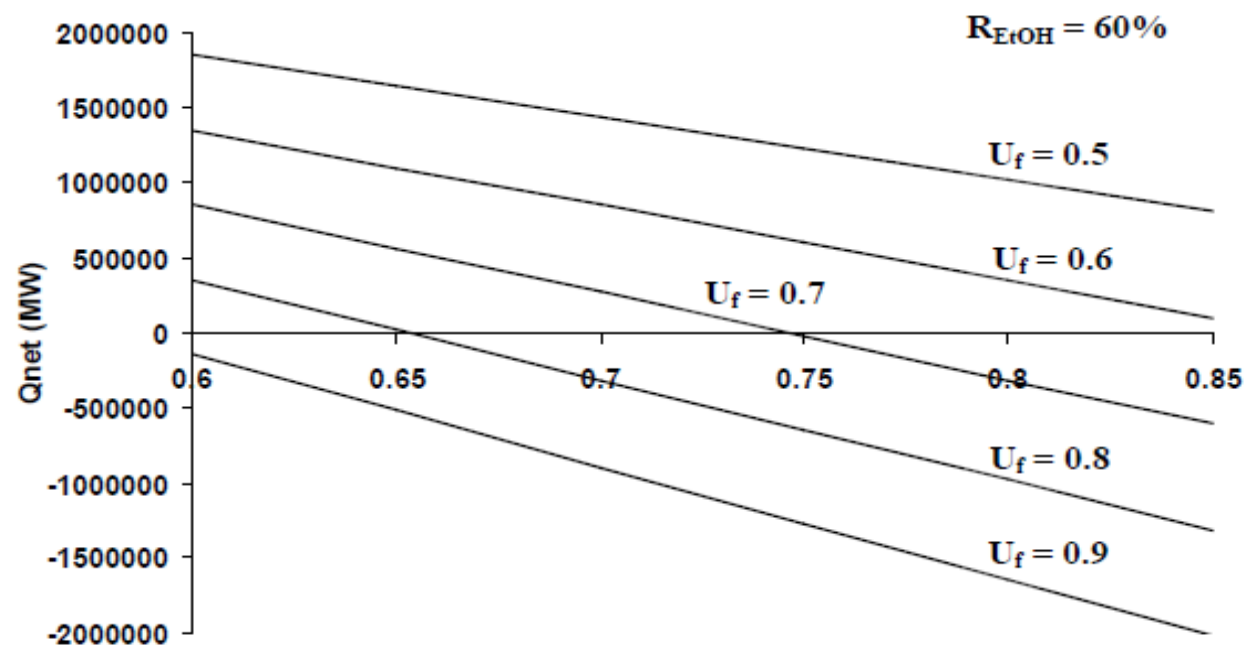

Operating Voltage (V)

Fig. 7. Effects of operating voltage and fuel utilization on $\mathrm{Q}_{\text {net }}$ at low ethanol recovery: (a) Hydrophobic vapor permeation, (b) Hydrophilic vapor permeation.

\section{Conclusions}

The performance of membrane assisted bioethanol-fuelled solid oxide fuel cell system was investigated. Vapor permeation was integrated with a hydrophobic pervaporation in order to obtain a desired ethanol concentration of $25 \mathrm{~mol} \%$ with higher ethanol recovery. It was demonstrated with hydrophilic type was a suitable membrane for vapor permeation as it can achieve a higher overall system electrical efficiency than that of the hydrophobic type, and the required membrane separation factor was also feasibly available in real membrane materials. Although a vacuum pump of hydrophilic vapor permeation consumed high electrical energy at a higher ethanol recovery to remove large amount of steam through a membrane, the total energy requirement was still less than the other case because heat utilized an energy more than use of electrical power. Furthermore, there were some conditions at which the system 
can be operated under energy self-sufficient mode by adjusting proper operating parameters. Based on PTMSP pervaporation, it can offer the overall electrical efficiency of about 2.4 times when installing an extra vapor permeation unit compared with the case using the pervaporation alone. However, this work was a preliminary investigation to demonstrate the potential improvement on the overall electrical efficiency of bioethanol-fuelled SOFC system. More detailed studies should be further carried out. For example, an economic analysis should be considered to evaluate the benefit of the membrane-assisted bioethanol-fuelled solid oxide fuel cell system.

Table 2. Efficiency comparison of SOFC system between before and after installing extra vapor permeation.

\begin{tabular}{|c|c|c|c|c|}
\hline $\begin{array}{l}\text { Membrane } \\
\text { Pervaporation }\end{array}$ & $\begin{array}{l}\text { Ethanol Recovery (\%) } \\
\text { (25mol\%ethanol) }\end{array}$ & $\begin{array}{l}\text { Fuel Utilization } \\
\qquad(\%)\end{array}$ & $\begin{array}{l}\mathrm{W}_{\mathrm{e}, \text { net }} \\
(\mathrm{MW})\end{array}$ & $\begin{array}{r}\text { Efficiency } \\
(\%)\end{array}$ \\
\hline $\begin{array}{l}\text { PTMSP [11] } \\
\left(\alpha_{\mathrm{E} / \mathrm{W}}=10.7\right)\end{array}$ & 31.16 & 67.75 & $1,765.7$ & 10.96 \\
\hline $\begin{array}{l}\text { PTMSP [11] } \\
\left(\alpha_{\mathrm{E} / \mathrm{W}}=10.7\right) \text { with } \\
\text { hydrophilic vapor } \\
\text { permeation } \\
\left(\alpha_{\mathrm{W} / \mathrm{E}}=125.2\right)\end{array}$ & 75 & 86.5 & $5,392.3$ & 26.56 \\
\hline $\begin{array}{l}\text { PDMS (ZSM-5 } \\
\text { mixed matrix) }[10] \\
\left(\alpha_{\mathrm{E} / \mathrm{w}}=15.5\right)\end{array}$ & 54 & 89.2 & $4,007.5$ & 23.96 \\
\hline $\begin{array}{l}\mathrm{ZSM}-5 / \alpha-\mathrm{Al}_{2} \mathrm{O}_{3}[12] \\
\left(\alpha_{\mathrm{E} / \mathrm{W}}=24\right)\end{array}$ & 71 & 95.3 & $5,666.25$ & 34.02 \\
\hline
\end{tabular}

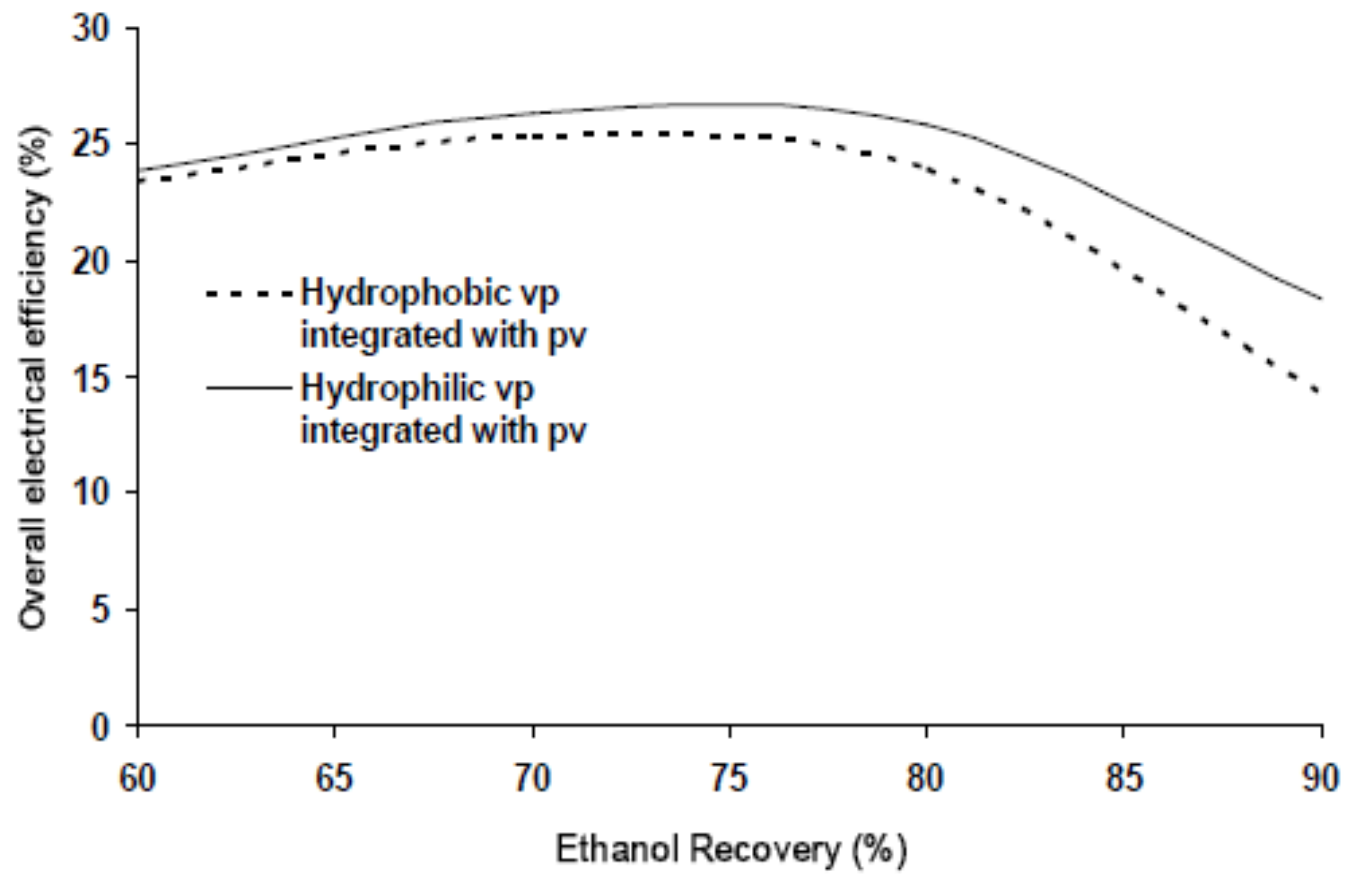

Fig. 8. Effect of ethanol recovery on overall electrical efficiency of two different membrane types of vapor permeation. 


\section{Acknowledgement}

The support from The National Research University Project of CHE and the Ratchadaphiseksomphot Endowment Fund (EN278A), National Metal and Materials Technology Center (MTEC) and National Science and Technology Development Agency (NSTDA) is gratefully acknowledged.

\section{References}

[1] H. L. Fleming, "Consider membrane pervaporation," Chemical Engineering Progress, vol. 46, 1992.

[2] M. E. Goldblatt and C. H. Gooding, "An engineering analysis of membrane-aided distillation," 1986, pp. 51-69.

[3] G. Rabenstein and V. Hacker, "Hydrogen for fuel cells from ethanol by steam-reforming, partial-oxidation and combined auto-thermal reforming: A thermodynamic analysis," Journal of Power Sources, vol. 185, pp. 1293-1304, 2008.

[4] H. J. Huang, S. Ramaswamy, U. W. Tschirner, and B. V. Ramarao, "A review of separation technologies in current and future biorefineries," Separation and Purification Technology, vol. 62, pp. 1-21, 2008.

[5] W. Jamsak, S. Assabumrungrat, P. L. Douglas, E. Croiset, N. Laosiripojana, R. Suwanwarangkul, and S. Charojrochkul, "Thermodynamic assessment of solid oxide fuel cell system integrated with bioethanol purification unit," Journal of Power Sources, vol. 174, pp. 191-198, 2007.

[6] I. Choedkiatsakul, S. Charojrochkul, W. Kiatkittipong, W. Wiyaratn, A. Soottitantawat, A. Arpornwichanop, N. Laosiripojana, and S. Assabumrungrat, "Performance improvement of bioethanol-fuelled solid oxide fuel cell system by using pervaporation," International Journal of Hydrogen Energy, 2011.

[7] R. W. Baker, Membrane Technology and Applications, 2nd ed.: John Wiley \& Sons Ltd., 2004.

[8] X. Lin, H. Kita, and K. I. Okamoto, "Silicalite membrane preparation, characterization, and separation performance," Industrial and Engineering Chemistry Research, vol. 40, pp. 40694078, 2001.

[9] X. Lin, H. Kita, and K. I. Okamoto, "A novel method for the synthesis of high performance silicalite membranes," Chemical Communications, pp. 1889-1890, 2000.

[10] R. W. Baker, J. G. Wijmans, and Y. Huang, "Permeability, permeance and selectivity: A preferred way of reporting pervaporation performance data," Journal of Membrane Science, vol. 348, pp. 346-352, 2010.

[11] J. R. González-Velasco, C. López-Dehesa, and J. A. González-Marcos, "Pervaporation performance of PTMSP membranes at high temperatures," Journal of Applied Polymer Science, vol. 90, pp. 2255-2259, 2003.

[12] H. Kita, "Pervaporation using zeolite membranes," in Proceedings of the International Workshop on Zeolitic Membranes and Films Post Conference of ICIM5, Gifu, Japan, 1998.

[13] I. Kumakiri, T. Yamaguchi, and S. I. Nakao, "Preparation of zeolite A and faujasite membranes from a clear solution," Industrial and Engineering Chemistry Research, vol. 38, pp. 4682-4688, 1999.

[14] M. Kondo, M. Komori, H. Kita, and K. I. Okamoto, "Tubular-type pervaporation module with zeolite NaA membrane," Journal of Membrane Science, vol. 133, pp. 133-141, 1997.

[15] T. Kaneko, J. Brouwer, and G. S. Samuelsen, "Power and temperature control of fluctuating biomass gas fueled solid oxide fuel cell and micro gas turbine hybrid system," Journal of Power Sources, vol. 160, pp. 316-325, 2006.

[16] P. Piroonlerkgul, S. Assabumrungrat, N. Laosiripojana, and A. A. Adesina, "Selection of appropriate fuel processor for biogas-fuelled SOFC system," Chemical Engineering Journal, vol. 140, pp. 341-351, 2008.

[17] F. Zhao and A. V. Virkar, "Dependence of polarization in anode-supported solid oxide fuel cells on various cell parameters," Journal of Power Sources, vol. 141, pp. 79-95, 2005. 
[18] G. Tao, T. Armstrong, and A. Virkar, "Intermediate temperature solid oxide fuel cell (ITSOFC) research and development activities at MSRI," in Nineteenth Annual ACERC\&ICES Conference, Utah, 2005.

[19] L. Petruzzi, S. Cocchi, and F. Fineschi, "A global thermo-electrochemical model for SOFC systems design and engineering," Journal of Power Sources, vol. 118, pp. 96-107, 2003.

[20] J. G. Wijmans and R. W. Baker, "The solution-diffusion model: A review," Journal of Membrane Science, vol. 107, pp. 1-21, 1995. 